\title{
Estimation of actual evapotranspiration of Mediterranean perennial crops by means of remote-sensing based surface energy balance models
}

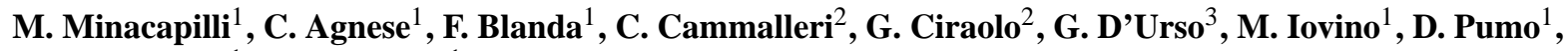 \\ G. Provenzano ${ }^{1}$, and G. Rallo ${ }^{1}$ \\ ${ }^{1}$ Dipartimento di Ingegneria e Tecnologie Agro-Forestali (ITAF), Università di Palermo, Italy \\ ${ }^{2}$ Dept. of Hydraulic Engineering and Environmental Applications, Università di Palermo, Italy \\ ${ }^{3}$ Dept. Agricultural Engineering and Agronomy, University of Naples "Federico II", Italy
}

Received: 24 October 2008 - Published in Hydrol. Earth Syst. Sci. Discuss.: 5 January 2009

Revised: 25 May 2009 - Accepted: 25 May 2009 - Published: 9 July 2009

\begin{abstract}
Actual evapotranspiration from typical Mediterranean crops has been assessed in a Sicilian study area by using surface energy balance (SEB) and soil-water balance models. Both modelling approaches use remotely sensed data to estimate evapotranspiration fluxes in a spatially distributed way. The first approach exploits visible (VIS), nearinfrared (NIR) and thermal (TIR) observations to solve the surface energy balance equation whereas the soil-water balance model uses only VIS-NIR data to detect the spatial variability of crop parameters. Considering that the study area is characterized by typical spatially sparse Mediterranean vegetation, i.e. olive, citrus and vineyards, alternating bare soil and canopy, we focused the attention on the main conceptual differences between one-source and two-sources energy balance models. Two different models have been tested: the widely used one-source SEBAL model, where soil and vegetation are considered as the sole source (mostly appropriate in the case of uniform vegetation coverage) and the twosources TSEB model, where soil and vegetation components of the surface energy balance are treated separately. Actual evapotranspiration estimates by means of the two surface energy balance models have been compared vs. the outputs of the agro-hydrological SWAP model, which was applied in a spatially distributed way to simulate one-dimensional water flow in the soil-plant-atmosphere continuum. Remote sensing data in the VIS and NIR spectral ranges have been used to infer spatially distributed vegetation parameters needed to
\end{abstract}

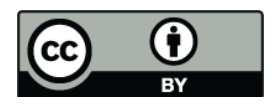

Correspondence to: M. Minacapilli (mario.minacapilli@unipa.it) set up the upper boundary condition of SWAP. Actual evapotranspiration values obtained from the application of the soil water balance model SWAP have been considered as the reference to be used for energy balance models accuracy assessment.

Airborne hyperspectral data acquired during a NERC (Natural Environment Research Council, UK) campaign in 2005 have been used. The results of this investigation seem to prove a slightly better agreement between SWAP and TSEB for some fields of the study area. Further investigations are programmed in order to confirm these indications.

\section{Introduction}

Estimation of evapotranspiration in Sicilian tree crops is a crucial emerging issue since these agricultural systems are more and more converted from rainfed to irrigated conditions, with significant impacts on the management of the scarse water resources of the region. The choice of the most appropriate methodology for assessing water use in these systems is still an issue of debating, due to the complexity of tree canopy and root system and for the high land fragmentation. During recent years, several procedures and models have been developed to simulate mass and energy exchange in the soil-plant-atmosphere (SPA) system (Feddes et al., 1978; Bastiaanssen et al., 2007). In particular, deterministic models have been proposed for detailed simulation of all the components of the water balance, including crop growth, irrigation and solute transport (Vanclooster et al., 1994; Van Dam et al., 1997; Droogers et al., 2000; Ragab,

Published by Copernicus Publications on behalf of the European Geosciences Union. 
2002). These models have been developed for site-specific applications but they have seldom been applied to large areas, due to the complexity in the acquisition of input data, often characterised by spatial and temporal variability. To overcome this problem, several techniques have been suggested which involve the use of GIS (Liu, 2009) and remote sensing to gather quantitative information on the temporal and spatial distribution of various vegetation parameters, i.e. albedo, crop coefficient, leaf area index (Choudhury et al., 1994; D'Urso et al., 1999; Schultz and Engman, 2000). The feasibility of using remotely sensed crop parameters in combination of agro-hydrological models has been investigated in recent studies (D'Urso, 2001; D'Urso and Minacapilli, 2006; Immerzeel et al., 2008; Crown et al, 2008; Minacapilli et al., 2008) with the aim of enabling the spatially distributed evaluation of water balance components in the SPA system.

A further contribution offered by remote sensing techniques has been the development of operational methods for the direct estimation of actual evapotranspiration based on the surface energy balance (SEB) approach, which exploits thermal infrared (TIR) observations of the earth's surface acquired from satellite and/or airborne platforms (Norman et al., 1995; Chehbouni et al., 1997; Bastiaanssen et al., 1998a, b; Su, 2002).

In the recent years, several SEB schemes have been developed (Schmugge et al., 2002) with varying degree of complexity that essentially involve two types of schematization: the "one-source" approach, that, according to the "big leaf" (Monteith, 1965) scheme, does not distinguish between soil evaporation and canopy transpiration and the recently applied "two-sources" approach which explicitly deals with the energy exchanges between the soil and vegetation and the overlaying atmosphere. Both approaches are hardly applied and compared under Mediterranean conditions since the traditional one-source approach is still the most widely applied.

The main object of our work is the comparison between two surface energy balance approaches, the one-source SEBAL model (Bastiaanssen et al., 1998a, b) and the TSEB two-sources model (Norman et al., 1995) to estimate the actual crop evapotraspiration in a spatially distributed way in an area located in the South West of Sicily and characterized by typical Mediterranean crops. The complexity of tree crop systems under study and the small dimension of plots imposes severe limitations to the application of micrometeorological techniques (eddy covariance or scintillometry instruments) for the validation of energy balance models. To overcome the above mentioned limitations, the actual crop evapotranspiration estimated by two different approaches has been compared with the results of a dynamic soil water balance model, considered as the "reference" ones. This choice stems from a number of considerations for the present casestudy: 1) the soil water balance approach is the main method to evaluate crop water use in these conditions; 2) the soil water model has been applied with detailed knowledge of most relevant processes and parameters; 3) the soil water balance results have been validated in three locations with in-situ measurements.

Of particular interest to this study is the use of airborne high-resolution $(3 \mathrm{~m} \times 3 \mathrm{~m})$ remote sensing data in the VIS/NIR and TIR regions providing detailed observations of spectral reflectance and radiometric temperature. The image acquisition has been taken during a field campaign carried out in 2005, where detailed data including soil and hydrological measurements have been collected. This field data set has been used to implement the soil water balance model SWAP (Van Dam et al., 1997) in a spatially distributed way. The output of SWAP has been validated by means of soil water content measurements. As such, the actual evapotranspiration estimated by SWAP has been considered as the "reference" in the comparison between SEBAL and TSEB energy balance models.

\section{Models description}

SEBAL, TSEB and SWAP models use different approaches to calculate actual evapotranspiration. Key differences and peculiarities of the models are described in the following subsections.

\subsection{SEBAL and TSEB models}

A first application of the models in the same study area can be found in Ciraolo et al. (2006) and in Minacapilli et al. (2007). A detailed description of SEBAL and TSEB models can be found in Norman et al. (1995), Bastiaanssen et al. (1998a, b), Kustas and Norman (1999), Bastiaanssen et al. (2005).

\subsubsection{Models similarities}

In both approaches, the evapotranspiration is derived in terms of instantaneous latent heat flux, $\lambda \mathrm{ET}\left(\mathrm{W} \mathrm{m}^{-2}\right)$, and it is computed as the residual of the surface energy balance equation:

$\lambda \mathrm{ET}=R_{n}-G_{0}-H$

where $R_{n}\left(\mathrm{~W} \mathrm{~m}^{-2}\right)$ is the total net radiation, $G_{0}\left(\mathrm{~W} \mathrm{~m}^{-2}\right)$ is the soil heat flux, and $H\left(\mathrm{~W} \mathrm{~m}^{-2}\right)$ is the sensible heat flux. Once $\lambda$ ET has been computed, the daily evapotranspiration $\mathrm{ET}_{d}\left(\mathrm{~mm} \mathrm{~d}^{-1}\right)$ is obtained by the time integration of instantaneous $\lambda$ ET by means of the evaporative fraction parameter, $\Lambda$ (Menenti and Choudhury, 1993):

$\Lambda=\frac{\lambda \mathrm{ET}}{R_{n}-G_{0}}$

Several studies (Brutsaert and Sugita, 1992; Crago, 1996) demonstrated that, within daytime hours, the $\Lambda(0-1)$ values are almost constant in time, thus allowing the use of $\Lambda$ as a temporal integration parameter. Other studies showed that $\Lambda$ could varies in time due to advective conditions, suggesting the use of hourly meteorological measurements to integrate 
(Allen et al., 2007a, b). For the study area advective conditions are unlikely, therefore we supposed the constancy of $\Lambda$. Following this hypothesis, the daily evapotranspiration, $\mathrm{ET}_{d}$ $\left(\mathrm{mm} \mathrm{d}^{-1}\right)$, has been derived using the equation:

$\mathrm{ET}_{d}=\Lambda \frac{R_{n, 24}}{\lambda}$

where $\lambda\left(\mathrm{MJ} \mathrm{Kg}^{-1}\right)$ is the latent heat of vaporization and $R_{n, 24}$ represents the averaged net daily radiation, that can be derived by direct measurement or by using the classical formulation proposed in FAO 56 paper (Allen et al., 1998).

In both models the estimation of total net radiation, $R_{n}$, can be obtained by computing the net available energy considering the rate lost by surface reflection in the shortwave $(0.3 / 2.5 \mu \mathrm{m})$ and emitted in the longwave $(6 / 100 \mu \mathrm{m})$ :

$R_{n}=(1-\alpha) R_{s w d}+\varepsilon_{0}\left(\varepsilon^{\prime} \sigma T_{a}^{4}-\sigma T_{0}^{4}\right)$

where $R_{s w d}\left(\mathrm{~W} \mathrm{~m}^{-2}\right)$ is the global incoming solar radiation, $\alpha(-)$ is the surface albedo, $\varepsilon$ ' is the atmospheric emissivity $(-), \varepsilon_{0}$ is the surface emissivity $(-), \sigma\left(\mathrm{W} \mathrm{m}^{-2} \mathrm{~K}^{-4}\right)$ is the Stefan-Boltzmann constant, $T_{a}(\mathrm{~K})$ is the air temperature, and $T_{0}(\mathrm{~K})$ is the surface temperature.

\subsubsection{Models differences}

The main difference in the two SEB models is in the way the remotely sensed radiometric temperature is used in the fluxes calculation. Whilst in the one-source approach the surface temperature is uniquely derived from the radiometric one, in the two-sources scheme there is a partitioning of soil and canopy temperature, depending on the fractional vegetation cover and observation angle. As a consequence, the entire calculation of energy flux densities consider soil and canopy as separate components. Particularly, in the TSEB model the total net radiation is split between canopy $\left(R_{n, c}\right)$ and soil $\left(R_{n, s}\right)$ components according the following equations:

$R_{n, s}=R_{n} \exp \left(-0.45 \mathrm{LAI} / \sqrt{2 \cos \left(\theta_{z}\right)}\right)$

$R_{n, c}=R_{n}-R_{n, s}$

where $R_{n}$ is obtained using Eq. (4) and $\theta_{z}$ is the solar zenith angle.

The soil heat flux, $G_{0}\left(\mathrm{~W} \mathrm{~m}^{-2}\right)$ can be expressed as a constant fraction $c_{g}(\approx 0.35)$ of the net radiation at the soil surface $R_{n, s}$.

In the SEBAL approach, $G_{0}$ is calculated empirically as a fraction of the net radiation using the following relationship:

$G_{0}=R_{n} \frac{T_{0}}{\alpha}\left(0.003 \alpha+0.006 \alpha^{2}\right) \times\left(1-0.98 \mathrm{NDVI}^{2}\right)$

where NDVI (Normalised Difference Vegetation Index) (-) is a simple radiometric index derived from red and nearinfrared bands (Crippen, 1990).
The major difference between SEBAL and SEBS concerns the computation of sensible heat flux, $H$. In the SEBAL model, following the bulk resistance or "one-source" approach for a natural surface, the basic equation for combined soil and canopy sensible heat flux, $H$, is given by:

$H=\frac{\rho c_{p}\left(T_{0 h}-T_{a}\right)}{R_{a h}}$

where $\rho\left(\mathrm{Kg} \mathrm{m}^{-3}\right)$ is the air density, $c_{p}$ is the specific heat of air $\left(\mathrm{J} \mathrm{Kg}^{-1} \mathrm{~K}^{-1}\right), T_{0 h}(\mathrm{~K})$ is the so-called "aerodynamic surface temperature" (Kalma and Jupp, 1990), defined as the air temperature "which satisfies the bulk resistance formulation for sensible heat transport, $H$ " (Kustas et al., 2007); $T_{a}(\mathrm{~K})$ is the air temperature at certain reference height, and $R_{a h}\left(\mathrm{~s} \mathrm{~m}^{-1}\right)$ is the total resistance to heat transport across the temperature difference $\left(T_{0 h}-T_{a}\right)$ that can be evaluated by the following equation (Brutsaert, 1982):

$R_{a h}=\frac{\left[\ln \left(\frac{z_{u}-d_{0}}{z_{0, M}}\right)-\psi_{M}\right] \cdot\left[\ln \left(\frac{z_{T}-d_{0}}{z_{0, H}}\right)-\psi_{H}\right]}{k^{2} \cdot u}$

where $d_{0}(\mathrm{~m})$ is the displacement height, $z_{0, M}$ and $z_{0, H}$ are two roughness parameters $(\mathrm{m})$ that can be evaluated as functions of the canopy height (Shuttleworth and Wallace, 1985), $u$ is the wind speed $\left(\mathrm{m} \mathrm{s}^{-1}\right)$ measured at height $z_{u}(\mathrm{~m}), \mathrm{k}$ is the von Karman's constant $(\approx 0.4), z_{T}$ is the height of the air temperature measurement, $\Psi_{H}(-)$ and $\Psi_{M}(-)$ are two stability correction functions for momentum and heat transfer, respectively. A detailed description of the above mentioned parameters can be found in Brutsaert (1982).

Since the aerodynamic surface temperature is usually unknown, the common approach used in various one-source schemes is to empirically relate the radiative surface temperature, $T_{r}$, to $T_{0 \mathrm{~h}}$ or directly to the term $\left(T_{0 \mathrm{~h}}-T_{a}\right)$. In particular, the SEBAL model introduces a linear relationship between $T_{r}$ and $\Delta T=\left(T_{0 \mathrm{~h}}-T_{a}\right)$ to be calibrated on the basis of the knowledge of two boundary conditions identified within the image itself ("anchor" pixels). Hence, a dry non evaporating area is identified and a latent heat flux equal to zero is considered $\left(H=R_{n}-G_{0}\right)$. In a wet area, i.e. a water body or a fully evaporating surface, it is assumed $H=0$. In these anchor pixels the $\Delta T$ values derived by the inversion of Eq. (8) and the $T_{r}$ values observed from the TIR remote observation are used to calibrate the coefficients $\mathrm{a}$ and $\mathrm{b}$ of the following linear relationship:

$\Delta T=a+b T_{r}$

Successively, Eq. (10) is applied to all the image pixels in order to compute $\Delta T$ from the corresponding $T_{r}$, and hence $H$ by using Eq. (8). Details of the procedure above can be found in Bastiaanssen et al. (1998a, b).

Differently, the two-sources TSEB model considers the contributions from the soil and the canopy separately and it uses a few additional parameters to solve for sensible heat 
$\mathrm{H}$ as the sum of the contribution of the soil, $H_{s}$, and of the canopy, $H_{c}$, according to the following equations:

$H=H_{s}+H_{c}$

$H_{c}=\rho c_{p}\left[\frac{T_{c}-T_{a}}{R_{a h}}\right]$

$H_{s}=\rho c_{p}\left[\frac{T_{s}-T_{a}}{R_{s}+R_{a h}}\right]$

In Eqs. (12) and (13) $T_{c}$ and $T_{s}(\mathrm{~K})$ are, respectively, the canopy and soil aerodynamic temperatures and $R_{S}\left(\mathrm{~s} \mathrm{~m}^{-1}\right)$ is the soil resistance to the heat transfer (Goudriaan, 1977; Norman et al., 1995; Kustas and Norman, 1999). In particular, assuming that the observed radiometric temperature, $T_{r}$, is a combination of soil and canopy temperatures, the TSEB model adds the following relationship (Becker and $\mathrm{Li}, 1990$ ) to the set of Eqs. (12) and (13):

$T_{r}=\left[f_{\theta} T_{C}^{4}+\left(1-f_{\theta}\right) T_{S}^{4}\right]^{1 / 4}$

where $f_{\theta}$ is the vegetation directional fractional cover (Campbell and Normann, 1998). Besides the adjustment for the angular dependence of thermal observations, TSEB does not require the linearity assumption introduced in SEBAL through Eq. (11).

The set of Eqs. (12), (13) and (14) includes four unknowns variables $\left(H_{c}, H_{s}, T_{c}\right.$, and $\left.T_{s}\right)$. As a first approximation, assuming that the vegetation is unstressed and transpiring at the potential rate, the TSEB model uses the Priestly-Taylor equation (Priestly and Taylor, 1972) to estimate the latent heat flux $\lambda \mathrm{ET}_{c}$ as:

$\lambda \mathrm{ET}_{c}=R_{n, c}-H_{c}=\alpha_{p} \frac{\Delta}{\Delta+\gamma} R_{n, c}$

where $\alpha_{p}(-)$ is the Priestly-Taylor parameter, which is initially set to 1.26 ("potential" condition) and progressively adjusted, as explained below. In Eq. (13) $\Delta$ is the slope of the saturation vapour pressure-temperature curve at $T_{C}\left(\mathrm{~Pa} \mathrm{~K}^{-1}\right)$ and $\gamma$ is the psychrometric constant. If the vegetation canopy is undergoing water stress, Eq. (15) will lead to an overestimation of $\lambda \mathrm{ET}_{c}$, which turns in a negative value of $E_{s}$. This problem is addressed by iteratively decreasing $\alpha_{p}$ in Eq. (15) until a positive $E_{s}$ is reached (Norman et al., 1995).

\subsection{The agro-hydrological SWAP model}

SWAP (Soil-Water-Atmosphere-Plant) is a one-dimensional physically based model for water, heat and solute transport in variably saturated soil, and includes modules to simulate irrigation and crop growth (Kroes et al., 2000). SWAP simulates the vertical soil water flow and solute transport in close interaction with crop growth. Richards' equation (Richards, 1931), including root water extraction, is applied to compute transient soil water flow:

$C(h) \frac{\partial h}{\partial t}=\frac{\partial}{\partial z}\left[K(h)\left(\frac{\partial h}{\partial z}+1\right)\right]-S(z)$
In Eq. $(16) h(\mathrm{~cm})$ is the soil water pressure head, $z(\mathrm{~cm})$ is the vertical coordinate, assumed positive upwards, $t$ (d) is time, $C\left(\mathrm{~cm}^{-1}\right)$ is the differential moisture capacity, $K(h)$ $\left(\mathrm{cm} \mathrm{d}^{-1}\right)$ is the soil hydraulic conductivity function and $S$ $\left(\mathrm{d}^{-1}\right)$ is the root water extraction rate. The numerical solution of Eq. (16) requires the definition of initial, upper and lower boundary conditions, as well as the knowledge of the soil hydraulic properties, i.e. the soil water retention curve, $\theta(h)$, and the soil hydraulic conductivity function, $K(h)$. These functions are usually expressed by using the parametric relationships of Van Genuchten (1980) and Mualem (1976).

The upper boundary condition is determined by potential evapotranspiration, irrigation and rainfall. The potential evapotranspiration rate $\mathrm{ET}_{p}\left(\mathrm{~mm} \mathrm{~d}^{-1}\right)$, that is obtained by the product of the crop coefficient $K_{c}(-)$ and the PenmanMonteith reference evapotranspiration rate, $\mathrm{ET}_{0}\left(\mathrm{~mm} \mathrm{~d}^{-1}\right)$ (Allen et al., 1998). In order to compute daily $\mathrm{ET}_{0}$ values, weather data of solar radiation, vapour pressure, wind speed and air temperature are required while the crop-specific $K_{c}$ coefficient can be obtained from the literature (Allen et al., 1998). In field conditions where crops partly cover the soil, the $\mathrm{ET}_{p}$ is partitioned into the potential soil evaporation $E_{p}$ $\left(\mathrm{mm} \mathrm{d}^{-1}\right)$ and the potential crop transpiration $T_{p}\left(\mathrm{~mm} \mathrm{~d}^{-1}\right)$ using the Leaf Area Index (LAI) as a function of crop development stage (Goudriaan, 1977; Belmans et al., 1983):

$E_{p}=\mathrm{ET}_{p} \exp \left(-K_{g r} \mathrm{LAI}\right)$

$T_{p}=\mathrm{ET}_{p}-E_{p}$

where $k_{g r}(-)$ is the extinction coefficient for global solar radiation (Campbell and Norman, 1998). Under wet soil conditions, the actual soil evaporation $\mathrm{E}\left(\mathrm{mm} \mathrm{d}^{-1}\right)$ is governed by the atmospheric demands, and equals $E_{p}$. Under dry soil conditions, $E$ is governed by the maximum soil water flux $E_{\max }\left(\mathrm{mm} \mathrm{d}^{-1}\right)$ in the topsoils, which can be quantified by Darcy's equation. As Darcy's equation can overestimate the actual soil evaporation flux (Van Dam, 2000), SWAP also computes the soil evaporation rate with empirical functions, $E_{\text {emp }}$ and determines actual evaporation rate $E$ by taking the minimum value of $E_{p}, E_{\max }$ and $E_{\mathrm{emp}}$. For this study, we used the empirical function of Black et al. (1969) to limit the soil evaporation rate. The actual transpiration rate $T$ $\left(\mathrm{mm} \mathrm{d}^{-1}\right)$ is governed by the root water extraction rate, that in the case of uniform root distribution, can be computed by the following equation:

$S(h)=\alpha_{w}(h) \frac{T_{p}}{\left|z_{r}\right|}$

in which $z_{r}(\mathrm{~cm})$ is the rooting depth and $\alpha_{w}(-)$ [0-1] is a reduction coefficient depending on soil water pressure head in the root zone that accounts for water deficit and oxygen stress (Feddes et al., 1978).

In this study, the application of SWAP has been carried out in a spatially distributed way, according to the procedure 


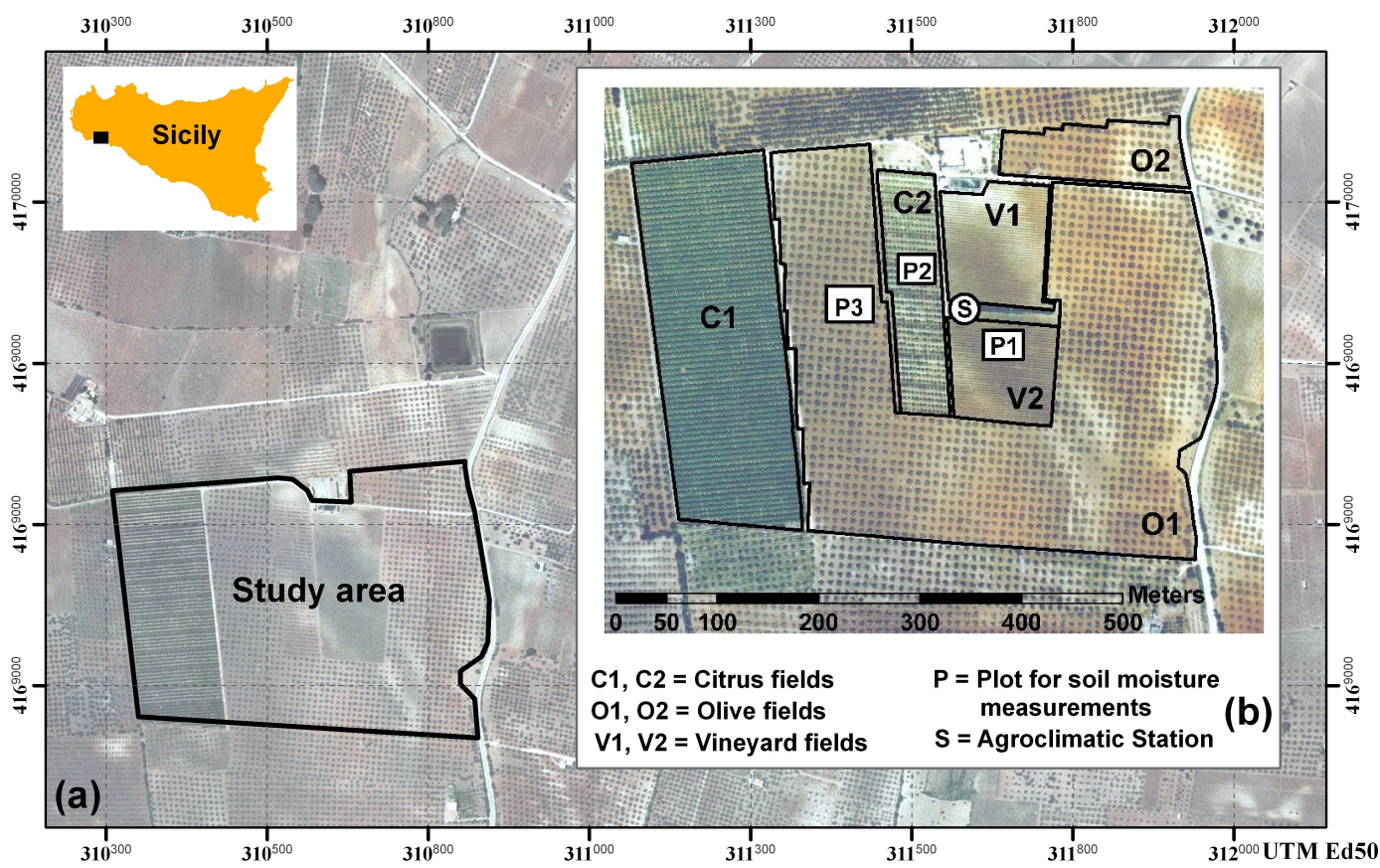

Fig. 1. Geographic location of the study area (a) with description of landuse and plots where the soil moisture measurements were acquired (b).

suggested by D'Urso (2001). The study area has therefore been discretized in individual one-dimensional units, with homogenous soil and canopy parameters. Canopy parameters such as LAI, albedo $(\alpha)$ and crop height $\left(h_{c}\right)$ have been determined by using remote sensing data to infer the spatial distribution of the crop coefficient $K_{c}$ using the analytical approach proposed by D'Urso et al. $(1999,2001)$. This approach consists of a direct application of the $\mathrm{K}_{c}$ theoretical expression:

$K_{c}=\frac{\mathrm{ET}_{p}}{\mathrm{ET}_{0}}$

where $\mathrm{ET}_{0}$ and $\mathrm{ET}_{p}$ are computed by Penman-Monteith equation (Allen et al., 1998) for grass reference $\left(\mathrm{ET}_{0}\right)$ and for the specified crop $\left(\mathrm{ET}_{p}\right)$, assuming the minimum value (non-stressed) for the canopy resistance $r_{c}\left(\mathrm{~s} \mathrm{~m}^{-1}\right)$. As $\mathrm{ET}_{0}$ depends only on meteorological data the variability of $K_{c}$ is related to the variability of crop parameters $\left(\alpha, r_{c}, \mathrm{LAI}, h_{c}\right)$ used for $\mathrm{ET}_{p}$ calculation. In this way $K_{c}$ can be expressed by:

$K_{c}=f\left(R_{s}, T_{a}, \mathrm{RH}, u_{z}, \alpha, r_{c}, \mathrm{LAI}, h_{c}\right)$

where $R_{S}$ is the incoming solar radiation, $T_{a}$ is the air temperature, RH is the air relative humidity, $u_{z}$ is the wind velocity. Thus, for a given set of climatic variables, using the above mentioned approach, the spatial distribution of $K_{c}$ and, consequently, of potential evapotranspiration have been derived, and this information have been used to define in each elementary unit the upper boundary condition of the soil water balance model SWAP, represented by Eq. (17). To take into account the spatial variability of the soil hydraulic properties standard interpolation techniques (Journel and Huijbregts, 1978) were used to obtain maps of soil hydraulic parameters required by SWAP from point measurements of $\theta(h)$ and $K(h)$. A detailed description of the entire procedure can be found in D'Urso (2001).

\subsection{Study area and data collection}

The study site considers an area of approximately $20 \mathrm{ha}$, located in the south-western coast of Sicily (Fig. 1). The area is dominated by olives, grapes and citrus. The soil can be classified as silty clay loam (USDA classification). During 2005, daily meteorological data (incoming short-wave solar radiation, air-temperature and humidity, wind speed and rainfall) have been acquired with standard meteorological instrumentations. A soil survey has been carried out to identify the main soil hydraulic parameters, needed as input in SWAP. Temporal variability of soil moisture contents in the different plots (Fig. 1) and at different depths was measured using a TDR device and a Diviner 2000 Sentek capacitive sensor. The Diviner 2000 Sentek sensor (Sentek, 2000) consists of a probe inserted in an access tube allowing to measure soil moisture content at different soil depths. In the grape test plot the access tubes were installed at 10,30 and $50 \mathrm{~cm}$ from the point receiving the irrigation supply. In the olive and citrus plots, where irrigation water is supplied with a microsprinkler system, a single access tube was installed at the 

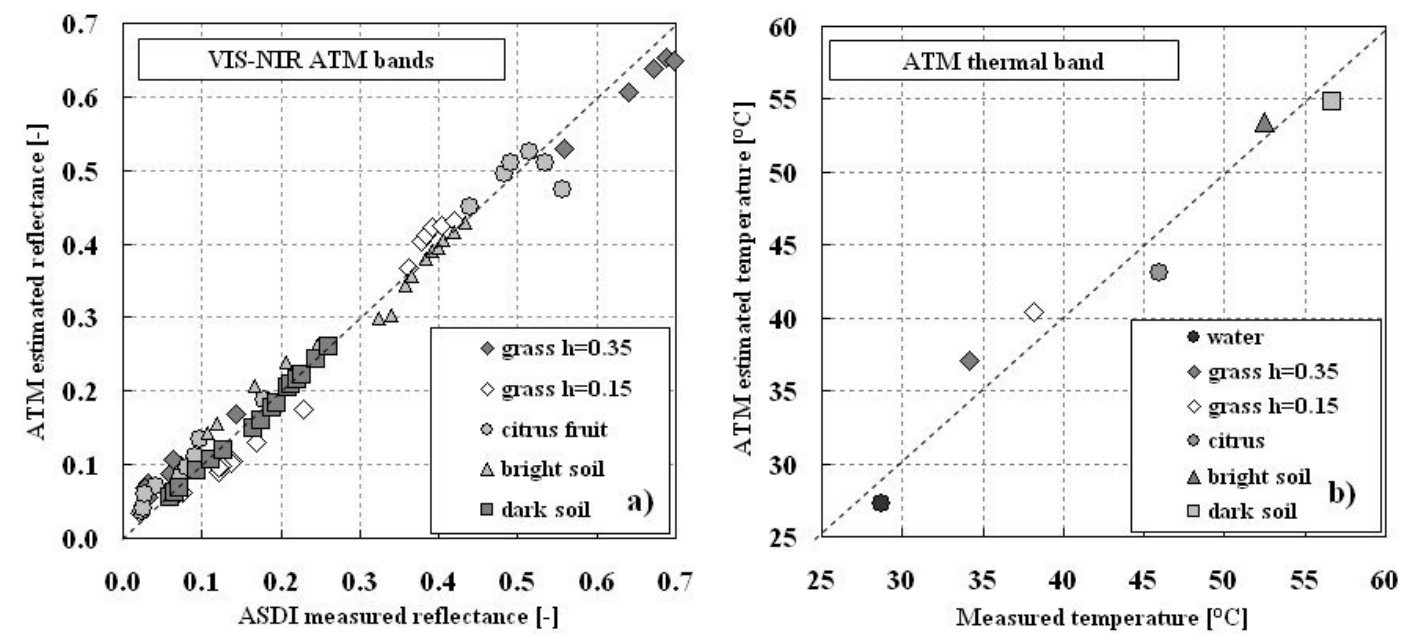

Fig. 2. Validation of correction procedures used to calibrate (a) VIS-NIR and (b) TIR ATM bands.

border of wetted zones. The measurements collected during the irrigation season have been used for validating SWAP in selected locations. Canopy parameters and radiometric surface temperatures have been acquired during an airborne campaign supported by NERC (National Environment Research Council, UK).

\subsection{Aircraft remote sensing processing}

\subsubsection{Pre-processing data}

The NERC airborne campaign has taken place on 16 May 2005 at about noon (local time). The flight altitude of $1400 \mathrm{~m}$ and the optical characteristics of the ATM sensor (Airborne Thematic Mapper) have produced images with a nominal spatial resolution (pixel size) of $3 \times 3 \mathrm{~m}$. ATM has 8 spectral bands in the visible and near-infrared ranges (VIS/NIR), 2 in the short-wave infrared (SWIR) and 1 in the thermal infrared region (TIR). At the same time of the acquisition flight, a field survey was carried out by measuring spectral and vegetation parameters corresponding to predefined homogeneous objects. Spectral measurements on water, bare soil and grass surfaces have been acquired by using an ASD (Analytical Spectral Device, Inc., Boulder, CO) FieldSpect HH spectroradiometer. These measurements have been used for the radiometric correction of the VIS-NIR images of ATM by using the empirical line method (Slater et al., 1996). The resulting surface reflectance values have been successively used to calculate the surface albedo and the vegetation indices. Nearsurface temperature measurements by means of a hand-held device have been made in selected locations simultaneously to the flight, in order to perform an empirical calibration of the thermal images acquired by the ATM sensor. The geometric correction of the entire data set has been performed using the NERC Azgcorr software (Azimuth System, 2003), that performs geocorrection of images using aircraft naviga- tion data and Digital Elevation Model (DEM) of the acquired zone. Calibrated reflectance and radiative temperature values as derived from the above mentioned pre-processing phase are shown in Fig. $2 \mathrm{a}$ and $\mathrm{b}$ for different land cover types.

\subsubsection{Canopy parameters detection}

As described in the Sect. 2 both SEB and SWAP models require the knowledge of a set of land surface and canopy parameters that were retrieved by means of spectral reflectance values acquired from the ATM VIS/NIR bands. Surface albedo has been computed as the weighted average over VIS and NIR reflectance bands of ATM (Liang, 2004). The LAI spatial distribution has been detected using the following semi-empirical relationship (Clevers, 1989):

$\mathrm{LAI}=-\frac{1}{\alpha^{*}} \ln \left(1-\frac{\mathrm{WDVI}}{\mathrm{WDVI}_{\infty}}\right)$

in which WDVI is a vegetation index derived from ATM red and near-infrared bands (Clevers, 1989), $\mathrm{WDVI}_{\infty}$ is the asymptotic value of WDVI for LAI $\rightarrow \infty$, and $\alpha^{*}$ is an extinction coefficient, denoting the increase of LAI for a unit increase of WDVI, that has to be estimated from simultaneous measurements of LAI and WDVI. In our case, the calibration of Eq. (22) was preliminarily carried out by in-situ LAI measurements collected with the portable instrument LAI2000 (Li-Cor, Lincoln, NE). A complete description of the leaf area index estimation conducted for the study area is given in Minacapilli et al. (2005, 2008). Furthermore, as suggested by other authors (Anderson et al., 2004) the crop height, $h_{c}$, has been calculated using a polynomial relationship between LAI and $h_{c}$.

Having derived $\alpha$, LAI and $h_{c}$ crop parameters, the pixel based spatial distribution of crop coefficients $K_{c}$ was directly derived following the analytical approach proposed by D'Urso (2001). The map of $K_{c}$ derived for the day of 


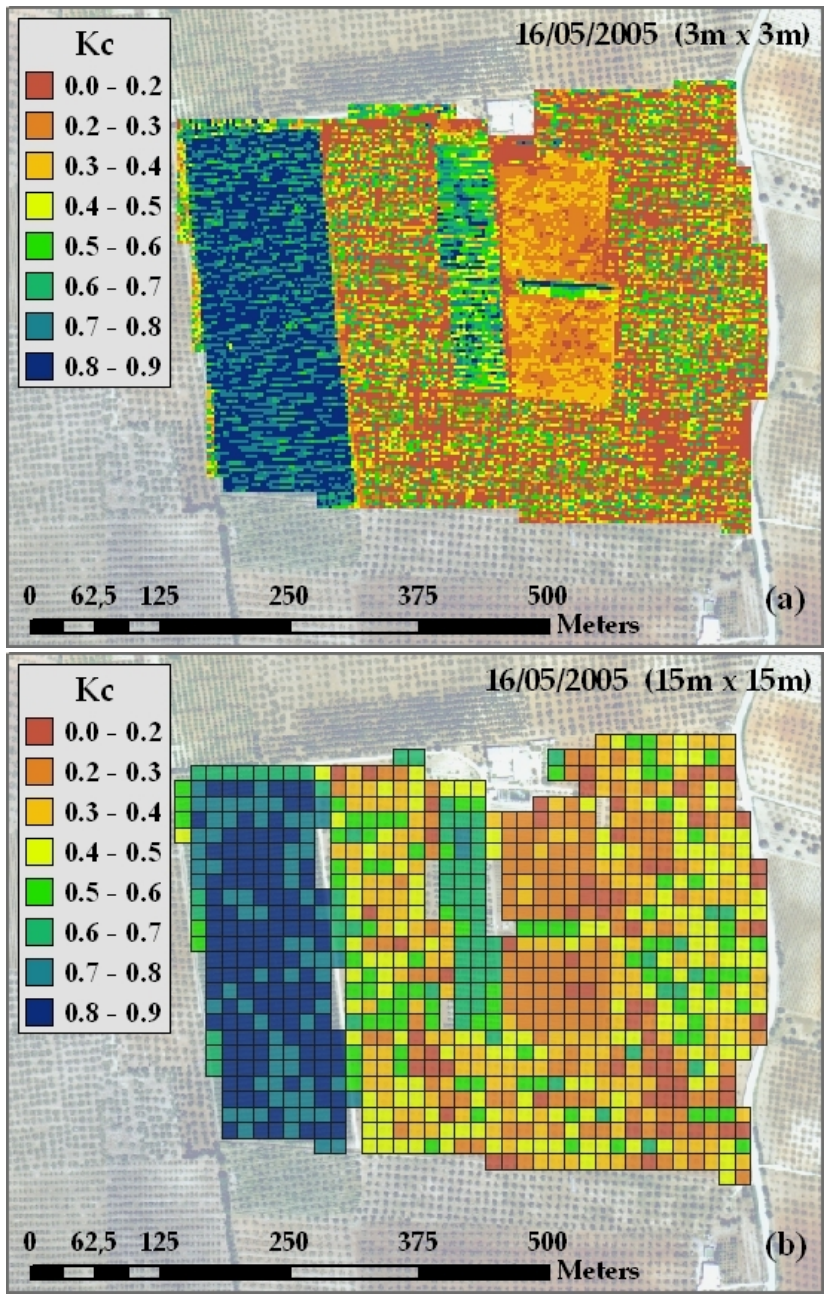

Fig. 3. Spatial distribution of crop factor, $K_{c}$, derived from the ATM image of 16 May 2005: (a) values at the spatial resolution of airborne image $(3 \mathrm{~m} \times 3 \mathrm{~m})$ and (b) aggregated using the grid reference of $15 \mathrm{~m} \times 15 \mathrm{~m}$ resolution used for the application of SWAP model in a spatially distributed way.

the NERC airborne overflight (16 May 2005, $J=135$ ) is displayed in Fig. 3a.

\subsection{SWAP model parameterization}

The minimum data-set required for the application of the SWAP model includes four main information types: i) soil hydraulic parameters, ii) lower boundary condition, defined by the groundwater table level or the water flux to or from an existing aquifer, iii) upper boundary conditions, i.e. rainfall and/or potential evapotranspiration, iv) soil moisture content or soil water pressure head profile for the initial condition. The soil hydraulic properties were deduced from laboratory measurements performed on undisturbed soil cores collected in texturally homogenous soils units, defined on the basis of
Table 1. Soil characteristics and hydraulic parameters according to Van Genuchten (1980).

\begin{tabular}{cccccc}
\hline $\begin{array}{c}\text { Layers depth } \\
(\mathrm{cm})\end{array}$ & $\begin{array}{c}K_{s} \\
\left(\mathrm{~cm} \mathrm{~d}^{-1}\right)\end{array}$ & $\begin{array}{c}\theta_{s} \\
\left(\mathrm{~m}^{3} \mathrm{~m}^{-3}\right)\end{array}$ & $\begin{array}{c}\theta_{r} \\
\left(\mathrm{~m}^{3} \mathrm{~m}^{-3}\right)\end{array}$ & $\begin{array}{c}n \\
(-)\end{array}$ & $\begin{array}{c}\alpha_{m g} \\
\left(\mathrm{~cm}^{-1}\right)\end{array}$ \\
\hline $0-20$ & 10 & 0.400 & 0.030 & 1.838 & 0.0104 \\
$20-40$ & 3 & 0.444 & 0.139 & 2.128 & 0.0118 \\
$40-60$ & 30 & 0.400 & 0.103 & 1.548 & 0.0159 \\
$60-180$ & 0.24 & 0.410 & 0.119 & 1.487 & 0.0460 \\
\hline
\end{tabular}

104 soil samples collected in the entire area. From the analysis of the spatial distribution of clay, silt and sand fractions, three experimental sites have been selected to determine the soil water retention curve and saturated hydraulic conductivity by analyzing undisturbed soil samples from various depths. The saturated hydraulic conductivity, $K_{S}\left(\mathrm{~cm} \mathrm{~d}^{-1}\right)$, has been determined by means of the constant head technique (Reynolds et al., 2002); soil water content $\theta$ has been determined for each pressure head value, $h$, ranging from -5 to $-15300 \mathrm{~cm}$ by means of a hanging water column apparatus (Burke et al., 1986) and a pressure plate apparatus (Dane and Hopmans, 2002). The water retention function of Van Genuchten (1980) has been fitted to the measured $\theta-h$ values by using the RETC (RETention Curve) code (Van Genuchten et al., 1991). The unsaturated hydraulic conductivity function has been derived by using the Mualem-Van Genuchten model (Van Genuchten, 1980). Due to the limited spatial variability of soil properties, it has been possible to consider an unique soil profile for the simulations of soil water balance in the study area (Table 1).

The soil moisture measurements collected during 2005 showed that a soil layer with low permeability is located from $1.2 \mathrm{~m}$ to lower depths. Therefore, the simulations were carried out considering a zero flux at the bottom of the soil profile.

The upper boundary condition, in terms of potential evapotranspiration $\mathrm{ET}_{p}\left(\mathrm{~mm} \mathrm{~d}^{-1}\right)$ was obtained multiplying the reference evapotranspiration $\left(\mathrm{ET}_{0}\right)$ by the crop coefficients $\left(K_{c}\right)$. In particular, the $K_{c}$ map values at the resolution of $3 \mathrm{~m} \times 3 \mathrm{~m}$ (Fig. 3a) were spatially averaged using a regular vector grid having a mesh size of $15 \mathrm{~m} \times 15 \mathrm{~m}$ (Fig. 3b) and used for the spatially distributed SWAP simulation.

Considering that citrus and olives are evergreen, the only ATM airborne surveys, acquired on 16 May 2005 has been assumed enough to derive their crop coefficients values to be used as input for the simulation period (15 April 2005-15 May 2005). As regard as grape, a lumped value of the crop coefficient was derived from the literature (Allen et al., 1998) by assuming a linear variation during the period of simulation. Others crop parameters required by SWAP, i.e. $k_{g r}, z_{r}$ and the critical pressure head values defining the reduction factor $\alpha_{w}$ in Eq. (19), were taken from literature (Taylor and Ashcroft, 1972; Doorenbos and Kassam, 1979; Wesseling et 

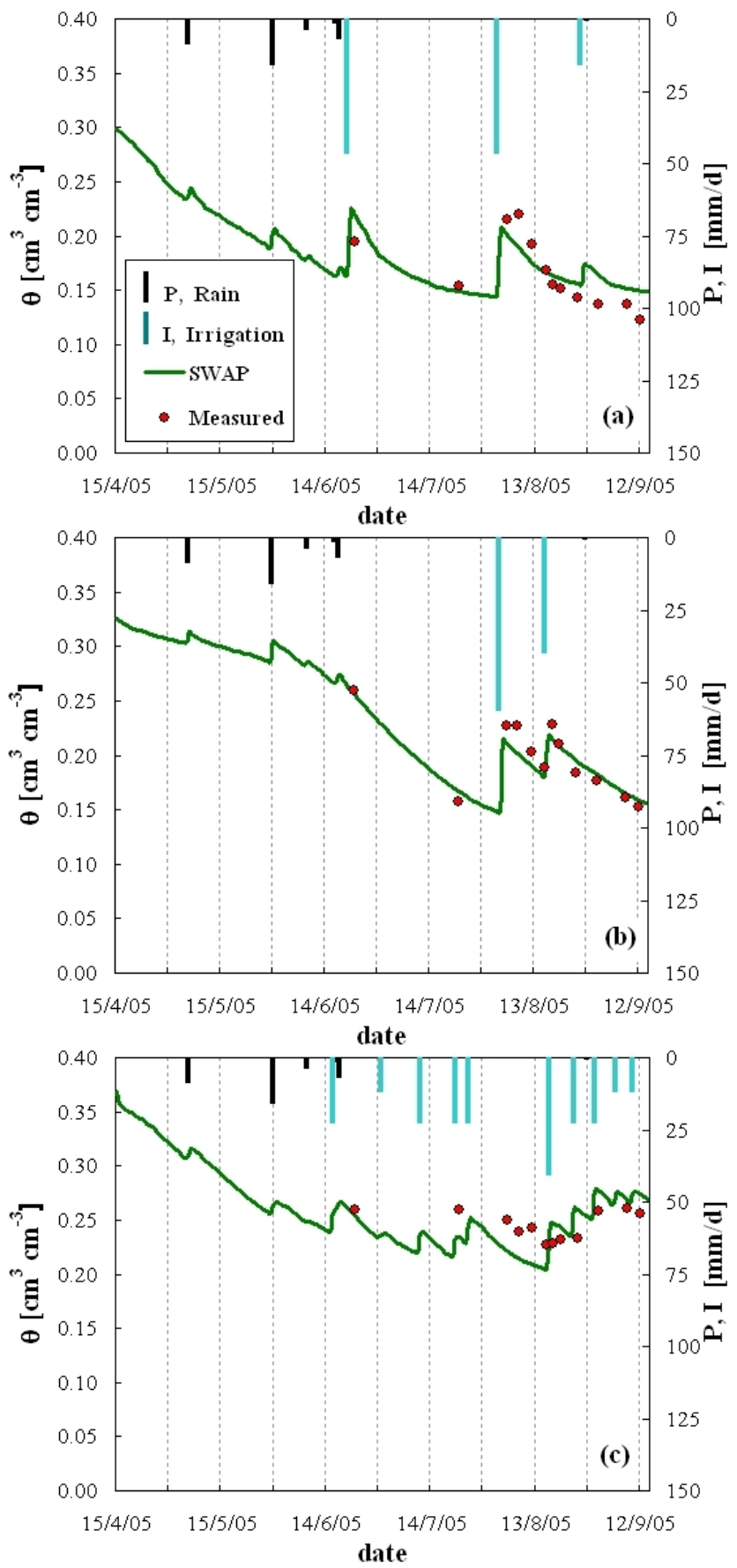

Fig. 4. Soil water balance validation at field scale: Comparison of simulated versus measured multitemporal soil water content at different locations; (a) Olive crop; (b) Vineyards crop; (c) Citrus crop.

al., 1991) with some minor adaptations based on local observations. Crop parameters for the case study used for the simulations are summarized in Table 2.
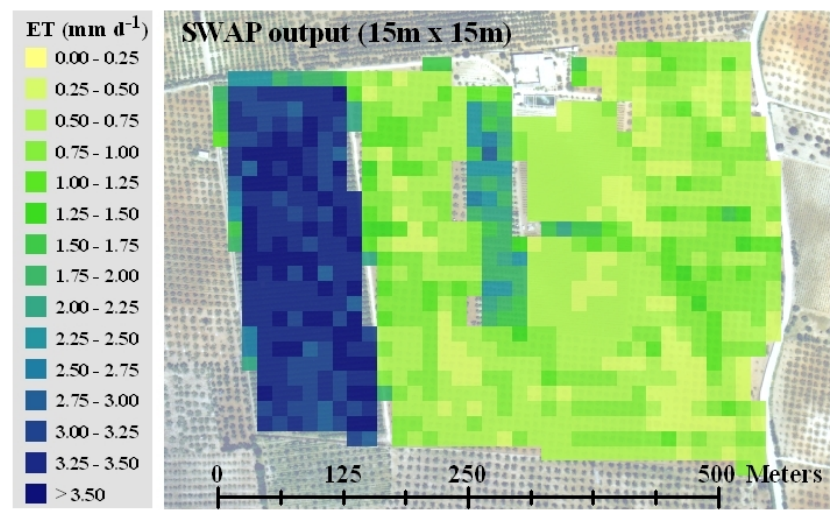

Fig. 5. Daily actual evapotranspiration map obtained from SWAP model on 16 May 2005.

\section{Results and discussion}

The following results focus on the crop evapotranspiration estimation using both energy (SEBAL and TSEB) and soilwater (SWAP) balance modelling approaches. In Sect. 3.1, the validation of SWAP model at field scale is discussed. Afterwards the application of SWAP model has been carried out in a distributed way to define the reference scenario to be used for the comparisons. Finally, in Sect. 3.2 the comparison of spatially distributed crop evapotranspiration estimated with the three different approaches is discussed, as well as the evaluation of the differences in fluxes prediction between SEBAL and TSEB.

\subsection{Validation of SWAP at field scale and its spatially distributed application}

The validation of SWAP has been carried out in three different locations inside the experimental farm (Fig. 1), where measurements of soil water content have been continuously acquired during the simulation period.

Figure 4 show the daily average soil water content, $\theta$ $\left(\mathrm{cm}^{3} \mathrm{~cm}^{-3}\right)$ in the root zone predicted by SWAP for the entire simulation period. The daily values of $\theta$ ranged from 0.15 to 0.35 with lower values in summer: during this period increases in soil moisture are due to the irrigation supplies. In Fig. $4 a-c$ the average water content measured in the same soil profile are shown. As can be observed for the three crops SWAP has been able to predict quite well the average soil water contents. The good accuracy of model was confirmed by the low RMSE (root mean square error) values varying in a very small range $(1.16-2.00 \%)$.

The presence of the low permeability layer at the bottom of the soil profile implies that the water exchanges occur mainly through the upper boundary of the profile. The good agreement between the simulated SWAP soil moisture values with the measured ones suggests that the simulated 
Table 2. Main crop parameters used for the simulations in the study area (standard deviation values are given in parentheses).

\begin{tabular}{|c|c|c|c|}
\hline Parameters & Vineyard & Olive & Citrus \\
\hline \multicolumn{4}{|l|}{ Crop factors $K_{c}$} \\
\hline$K_{c}$ at simulation starting date (15 Apr 2005$)$ & $0.25^{\mathrm{a}}$ & 0.62 & 0.75 \\
\hline$K_{c}$ at simulation ending date (15 May 2005) & 0.35 & 0.62 & 0.75 \\
\hline \multicolumn{4}{|l|}{ Critical pressure heads $(\mathrm{cm})$} \\
\hline$h_{2}$ ( $h$ below which optimum water uptake starts in the root zone) & -25 & -25 & -25 \\
\hline $\begin{array}{l}h_{3 h} \text { ( } h \text { below which optimum water uptake reduction starts in the root } \\
\text { zone in case of high atmospheric demand) }\end{array}$ & -750 & -1500 & -200 \\
\hline $\begin{array}{l}h_{3 l} \text { ( } h \text { below which optimum water uptake reduction starts in the root } \\
\text { zone in case of low atmospheric demand) }\end{array}$ & -1500 & -1500 & -1000 \\
\hline$h_{4}$ (wilting point, no water uptake at lower pressure heads) & -10000 & -16000 & -10000 \\
\hline Treshold level of high atmospheric demand $\left(\mathrm{mm} \mathrm{d}^{-1}\right)$ & 5 & 5 & 5 \\
\hline Treshold level of low atmospheric demand $\left(\mathrm{mm} \mathrm{d}^{-1}\right)$ & 2 & 2 & 2 \\
\hline$k_{g r}($ extinction coefficient $)(-)$ & 0.45 & 0.50 & 0.45 \\
\hline$z_{r}$ (soil depth where root density is maximum) $(\mathrm{cm})$ & $60-70$ & $40-60$ & $40-60$ \\
\hline
\end{tabular}

a from Allen et al. (1998)

Table 3. Crop averaged evapotranspiration components $\left(\mathrm{mm} \mathrm{d}^{-1}\right)$ in the day when the airborne overpassed (16 May 2005$)$ obtained using SWAP model; the coefficients of variation $(\%)$ are given in parentheses.

\begin{tabular}{lcccccc}
\hline Output SWAP & & \multicolumn{2}{c}{ 16 May 2005 $(J=135)$} & & \\
& Citrus $(\mathrm{C} 1)$ & Citrus $(\mathrm{C} 2)$ & Olive $(\mathrm{O} 1)$ & Olive $(\mathrm{O} 2)$ & Vineyard (V1) & Vineyard (V2) \\
\hline Evaporation $\left(\mathrm{mm} \mathrm{d}^{-1}\right)$ & $0.30(3.8)$ & $0.29(0.1)$ & $0.32(6.2)$ & $0.31(5.8)$ & $0.33(0.1)$ & $0.34(0.1)$ \\
Transpiration $\left(\mathrm{mm} \mathrm{d}^{-1}\right)$ & $2.92(15.5)$ & $1.43(41.8)$ & $0.42(60.5)$ & $0.39(24.5)$ & $0.26(34.6)$ & $0.29(44.7)$ \\
Evapotranspiration $\left(\mathrm{mm} \mathrm{d}^{-1}\right)$ & $3.23(13.7)$ & $1.72(34.2)$ & $0.74(34.8)$ & $0.70(14.6)$ & $0.59(8.6)$ & $0.61(21.2)$ \\
\hline
\end{tabular}

evapotranspiration values can be considered as a good approximation of the real ones.

On the basis of the above assumption we applied the SWAP model to the entire study area using the spatially distributed approach described in the Sect. 3.2 in order to produce a spatial distribution of simulated daily evapotranspiration values at 16 May 2005 that is used as reference for the comparison between SEBAL and TSEB models (see Fig. 5). A summary of the values obtained for each plot is given in Table 3. For citrus fields the evapotranspiration ranges from 1.72 to $3.23 \mathrm{~mm} \mathrm{~d}^{-1}$, whereas for the olive and vineyard fields the values resulted in the ranges 0.70 to $0.74 \mathrm{~mm} \mathrm{~d}^{-1}$ and 0.59 to $0.61 \mathrm{~mm} \mathrm{~d}^{-1}$, respectively.

\subsection{Estimating ET by SEB models and final comparison}

The two surface energy balance models have been applied by using VIS/NIR and TIR data acquired during the NERC campaign on 16 May 2005 as described in Sect. 2.1. In order to compare ET maps obtained by SEBAL and TSEB with SWAP reference values, the SEB models outputs have been spatially aggregated using the same $15 \mathrm{~m} \times 15 \mathrm{~m}$ grid adopted in SWAP. The resulting ET maps are displayed in Fig. 6. By comparing these maps with the SWAP one (Fig. 5) it is possible to recognize a slightly greater spatial variability in the SEB ET outputs, although minima and maxima values are similar to those estimated by SWAP. Moreover all the three models are able to capture the different behaviours of each crop type. The performance of SEBAL and TSEB has been evaluated by computing the mean ET difference maps (on a $15 \mathrm{~m} \times 15 \mathrm{~m}$ grid cell) between SWAP and SEBAL and SWAP and TSEB. Maps presenting the spatial distribution of difference values are shown in Fig. $6 \mathrm{c}$ and d: for both models difference values range from -2.5 to $2.5 \mathrm{~mm} / \mathrm{d}$ with a smaller mean value using TSEB $(-0.14 \mathrm{~mm} / \mathrm{d})$ compared to SEBAL $(-0.55 \mathrm{~mm} / \mathrm{d})$. The spatial distributions of difference allow to identify where the largest discrepancies occur. In particular, ET values in the olive O1 field appear almost homogeneous for SWAP and TSEB, whereas ET values estimated by SEBAL are lower in the western part of this field. This behaviour can be explained by the fact that in this area the canopy is slightly sparser than in the eastern one. This affects the spatial distribution of the radiometric temperature that, as consequence, is slight higher. The SEBAL one-source approach use these temperatures as canopy temperatures and it computes a sensible heat flux higher than the real one. 


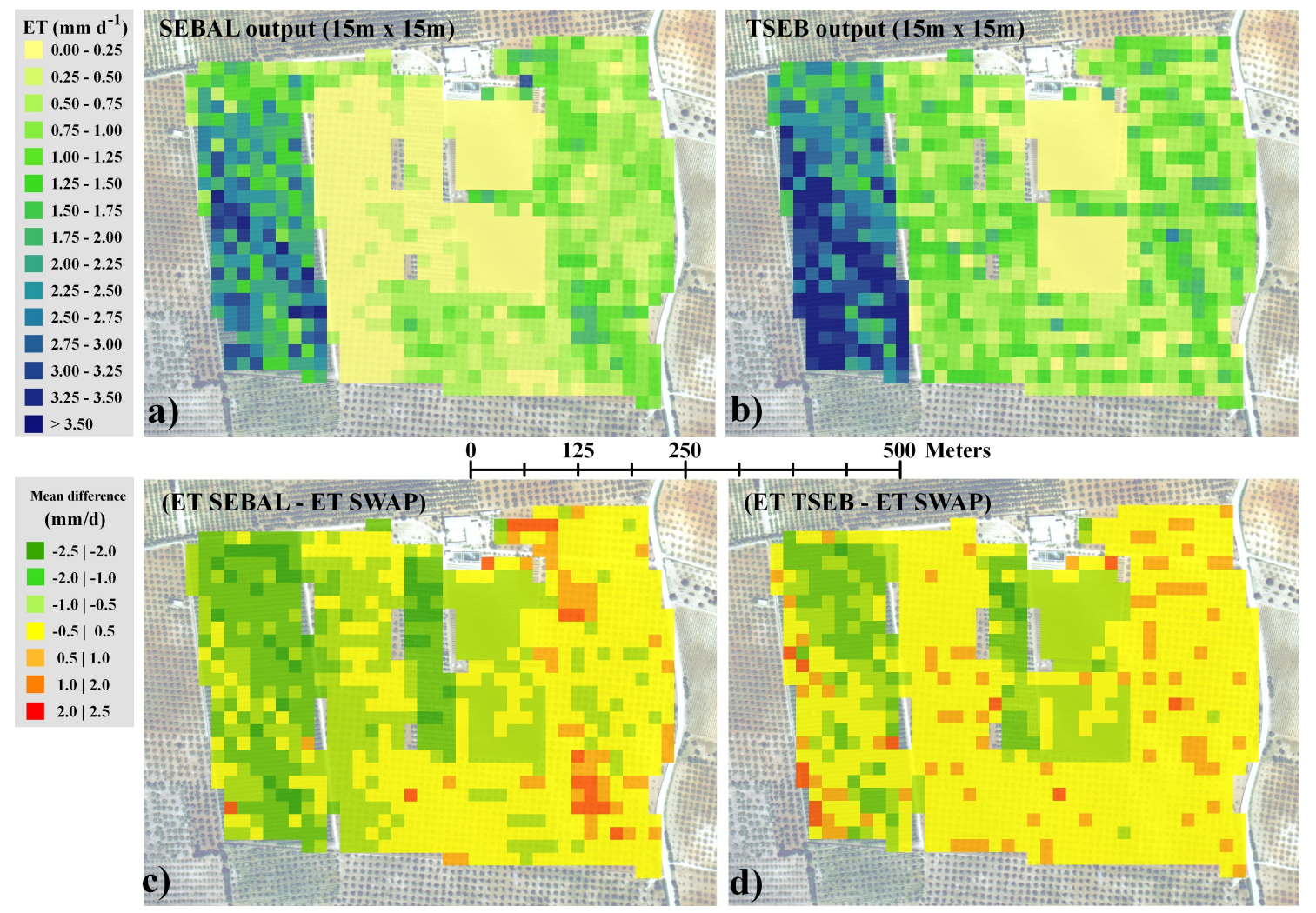

Fig. 6. Spatial distributions $(15 \mathrm{~m} \times 15 \mathrm{~m}$ resolution) of evapotranspiration rates obtained using (a) the SEBAL model and (b) the TSEB model. Spatial distribution of the differences between (c) SEBAL and SWAP models and (d) TSEB and SWAP models.

Another discrepancy can be observed in the citrus C2 field and in the two vineyard fields where both TSEB and SEBAL depict lower ET values compared to SWAP. This underestimation is mainly due to pixel dimension $(3 \mathrm{~m} \times 3 \mathrm{~m})$ that resulted too coarse to capture correctly the size of these plants. The citrus $\mathrm{C} 2$ field is a young citrus grove with very small trees and, on May, vineyard is on the initial development stage and has a strong row architecture. In these conditions the green part of canopy occupied only a small part of each pixel producing temperature values near to bare soil ones.

The above consideration on the effect of pixel size in the detection of temperatures in the $\mathrm{C} 2$ field and in the two vineyard fields are not valid for the visible (VIS) and near infrared bands (NIR) used in the SWAP model to compute the spatial variability of $K_{c}$ by means of Eq. (21). The latter because the differences between soil and vegetation VIS/NIR signatures are lower compared to their temperature differences. In other terms for these fields pixel size affects mainly temperature rather than $K_{c}$ retrieved values. For these reasons SWAP provided more accurate estimation of ET also using the $15 \times 15 \mathrm{~m}$ grid size.

The discrepancies in the estimation of ET between SEBAL and the SWAP can be also argued from the analysis of frequency distribution of difference values between SEB and SWAP modelled evapotranspiration rates (Fig. 7a-d). In fact, as can be observed, over sparsely vegetated surfaces $(0.5<\mathrm{LAI}<2.5)$ SEBAL disagrees with SWAP more than TSEB.

The analysis of the observed discrepancies suggests that over sparsely vegetated surfaces, SEBAL produces lower ET compared to TSEB and SWAP. This disagreement can be quantified by giving a closer look to the values of the different terms of the energy balance, as shown in Fig. 8, where maps and scatterplots of sensible heat flux $H$ and soil heat flux $G_{0}$ are represented. In this figure it may be noticed that, when compared to TSEB, SEBAL provides higher values for $H$, which is not compensated by the opposite behaviour of $G_{0}$. This effect, which has been already observed in other similar studies (Savige et al., 2005; Ciraolo et al., 2006; Minacapilli et al., 2007; Gao and Long, 2008), has been related to an underestimation of the total resistance to the heat transport over sparsely vegetated surface, since SEBAL does not take into account the soil-canopy interactions. Diversely, the partitioning between soil and canopy in TSEB is able to provide a more physically-based picture of the surface resistances involved. As a result, being the available energy $\left(R_{n}-G_{0}\right)$ quite similar between the two models, the greater values of sensible heat flux in SEBAL is mainly responsible for the disagreement in $\lambda$ ET shown in Fig. 9 where a pixelwise scatterplot of the daily ET values obtained with the two 

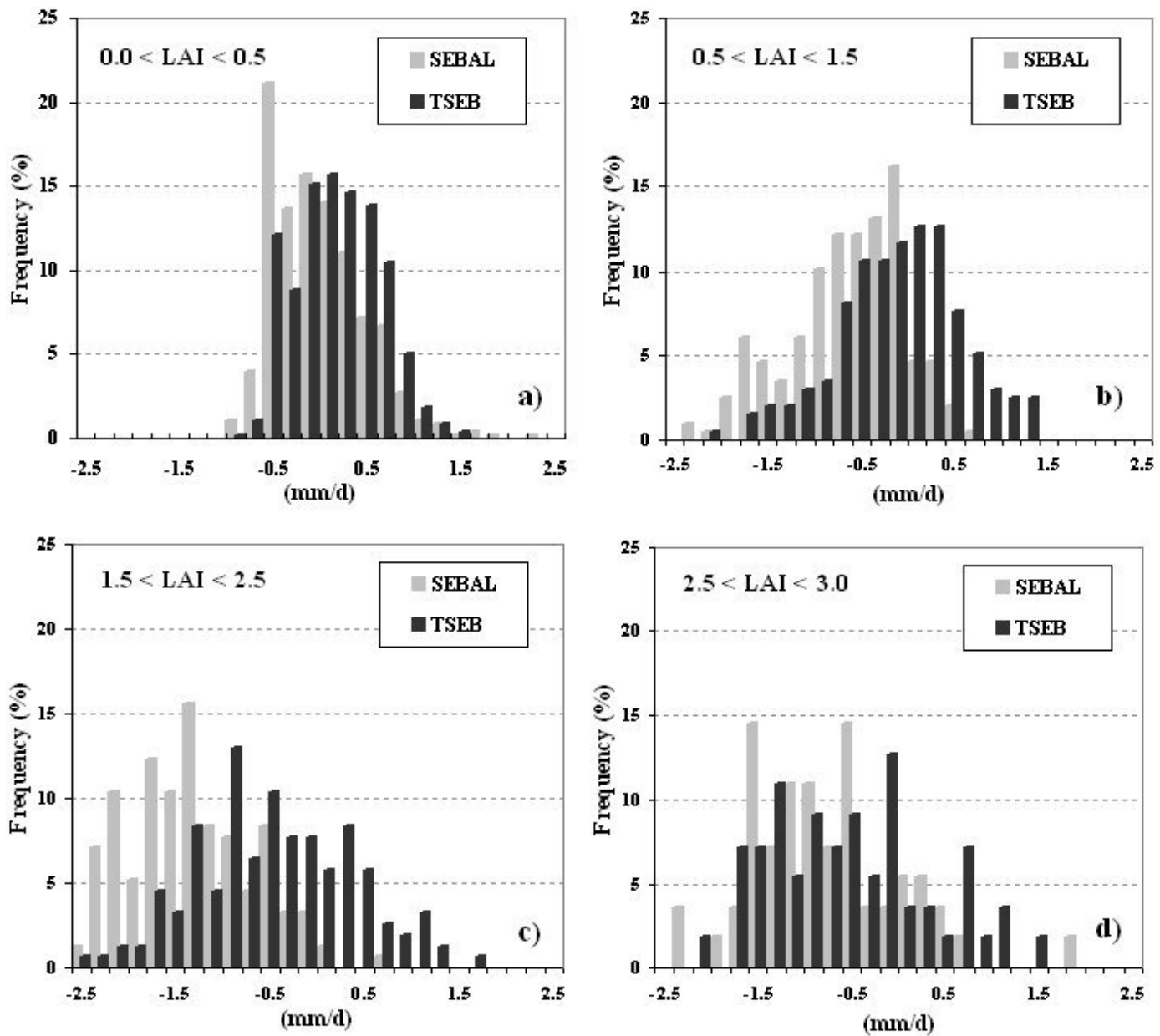

Fig. 7. Frequency distribution of difference values between SEBAL/TSEB and SWAP modelled evapotranspiration rates.

models is displayed. This plot evidences that SEBAL produces an underestimation of ET compared to TSEB of about $1 \mathrm{~mm} \mathrm{~d}^{-1}$.

Finally, the Fig. 10 shows the comparison between field average evapotranspiration ET obtained with SWAP, SEBAL and TSEB models. From this final comparison ET values lower than 50\% respect to SWAP estimations have been obtained by both SEB models for three cases over six (C2, V1 and V2). In the other cases a slightly better agreement can be recognized between SWAP and TSEB. These results do not allow to identify the most appropriate model. Therefore further investigations based on several remote sensing acquisitions in different vegetation growth stages and in situ measurements have to be carried out.

\section{Conclusions}

The main aim of this study was the test of two different methodologies for the assessment of the spatial distribution of ET by means of remote sensing data. The first consid- ered approach was a water balance model of the soil-plantatmosphere system able to computes the actual evapotranspiration as a sum of actual soil evaporation and canopy transpiration (SWAP). The second approach is based on the resolution of the surface energy balance (SEB) using two different models: the two-sources TSEB model, where soil and vegetation components of the surface energy balance are treated separately, and the widely used one-source SEBAL model, where soil and vegetation are considered as a sole source. As the application of micrometeorological techniques (eddy covariance or scintillometry instruments) for the validation of energy balance models imposes intense efforts, the two different SEB models have been compared with the results of the soil water balance model that was considered as the actual "reference". This choice was based on the fact that, for the study area, the soil water model has been applied with detailed knowledge of most relevant processes and parameters and validated with a large number of in-situ measurements.

Results showed that both SEB models were able to describe the ET spatial patterns of the different crop types providing ET values in the same range. In three cases out of 

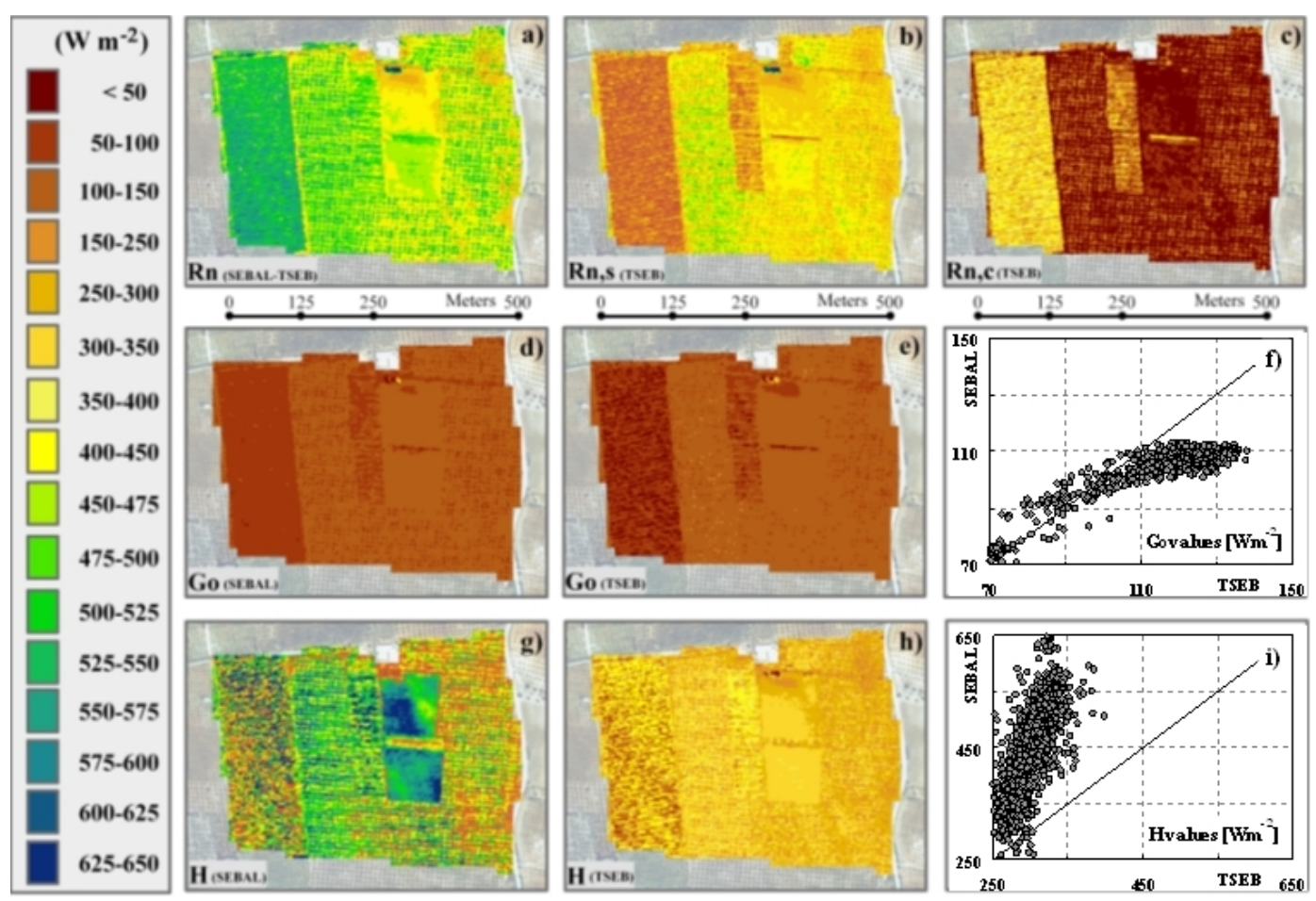

Fig. 8. Instantaneous energy balance fluxes obtained using SEBAL and TSEB models; scatterplots of SEBAL versus TSEB soil heat flux, $G_{0}, \mathrm{f}$ ) and sensible heat flux, $\left.H, \mathrm{i}\right)$.

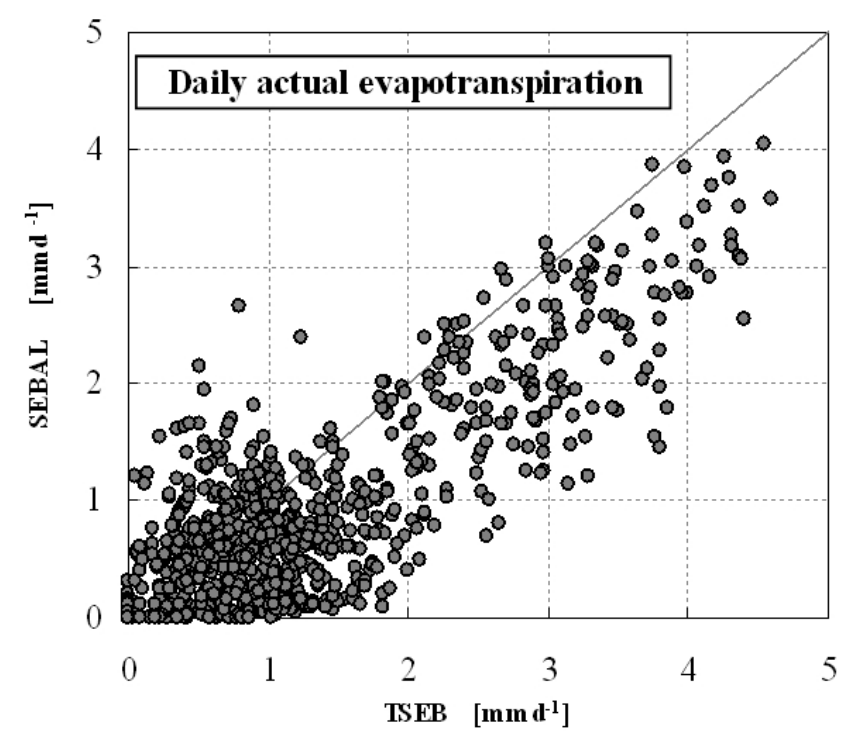

Fig. 9. Scatterplots of SEBAL versus TSEB evapotranspiration outputs.

six the ET values obtained by both SEB models were smaller tham those obtained by SWAP by a factor of two ore more. In the other cases a slightly better agreement can be recognized between SWAP and TSEB. This analysis does not allow to determine which SEB model produce better performance in

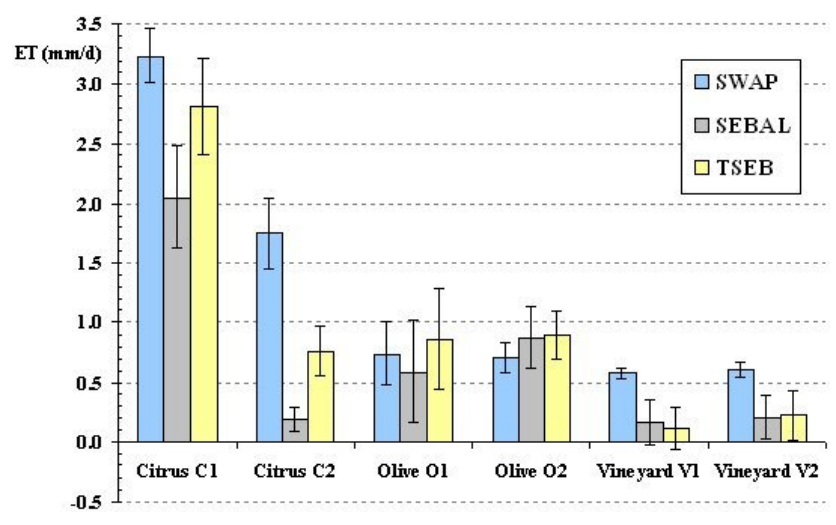

Fig. 10. Comparison between field averaged evapotranspiration estimates (lines represent the range of \pm 0.5 standard deviations).

our study case. The validity of these results are limited to the single remote sensing acquisition available and need to be confirmed by means of further investigations using a time series of acquisitions.

Acknowledgements. The research was supported by grants from Università di Palermo, Ministero dell'Istruzione dell'Università e della Ricerca (PRIN PUMO 2006) and Assessorato Agricoltura e Foreste Regione Sicilia (AGROIDROLOGIA SICILIA 2007). The authors thank the National Environment Research Council (NERC), UK, which provided the airborne imagery data-set in the 
framework of the project "Assimilation of Remote Sensing data in Hydrological Models", NERC Airborne Remote Sensing Facility Proposal 2003-04.

Edited by: J. Liu

\section{References}

Allen, R. G., Tasumi, M., and Trezza, R.: Satellite-based energy balance for mapping evapotranspiration with internalized calibration (METRIC)-Model, ASCE J. Irrig. Drain. Eng., 133(4), 380-394, 2007.

Allen, R. G., Tasumi, M., Morse, T. A. R., Wright, J. L., Bastiaanssen, W., Kramber, W., Lorite, I., and Robison, C. W.: Satellite-Based Energy Balance for Mapping Evapotranspiration with Internalized Calibration (METRIC) - Applications, J. Irrig. Drain. Engrg., 133, 395-406, 2007.

Allen, R. G., Pereira, L. S., Raes, D., and Smith, M.: Crop evapotranspiration. Guidelines for computing crop water requirements, FAO Irrigation and Drainage Paper (56), Rome, Italy, 1998.

Azimuth System: AZGCORR User's Manual for AZGCORR Version 4.0.0, Azimuth Systems UK, 1-39, 2003.

Anderson, M. C., Neale, C. M. U., Li, F., Norman, J. M., Kustas, W. P., Jayanthi, H., and Chavez, J.: Upscaling ground observations of vegetation water content, canopy height, and leaf area index during SMEX02 using aircraft and Landsat imagery, Rem. Sens. Environ., 92, 447-464, 2004.

Bastiaanssen, W. G. M., Noordman, E. J. M., Pelgrum, H., Davids, G., and Allen, R. G.: SEBAL for spatially distributed ET under actual management and growing conditions, ASCE J. Irr. Drain. Eng., 131(1), 85-93, 2005.

Bastiaanssen, W. G. M., Menenti, M., Feddes, R. A., and Holtslag, A. A. M.: The Surface Energy Balance Algorithm for Land (SEBAL): Part 1 formulation, J. Hydrol., 212(213), 198-212, 1998a.

Bastiaanssen, W. G. M., Pelgrum, H., Wang, J., Ma, Y., Moreno, J., Roerink, G. J., and Van der Wal, T.: The Surface Energy Balance Algorithm for Land (SEBAL): Part 2 validation, J. Hydrol., 212(213), 213-229, 1998b.

Bastiaanssen, W. G. M., Allen, R. G., Droogers, P., D’Urso, G., and Steduto, P.: Twenty-five years modeling irrigated and drained soils: State of the art, Agric. Water Manage., 92, 111-125, 2007.

Becker, F. and Li, Z. L.: Temperature-independent spectral indices in thermal infrared bands, Rem. Sens. Environ., 32, 17-33, 1990.

Blanda, F.: Indagini sperimentali e modellistica dei processi agroidrologici di colture tipiche dell' ambiente mediterraneo (Experimental researches and agrohydrological modeling of typical Mediterranean crops, $\mathrm{PhD}$ thesis dissertation), Università di Palermo, Dottorato in Idronomia Ambientale, 124 pp., 2005 (in Italian with English abstract).

Brutsaert, W. and Sugita, M.: Regional surface fluxes from satellitederived surface temperatures (AVHRR) and radiosonde profiles, Bound. Lay. Meteorol., 58, 355-366, 1992.

Brutsaert, W.: Evaporation into the Atmosphere. Theory, History and Applications, D. Reidel Publ. Co., Dordrecht, The Netherlands, 1982.

Burke, W., Gabriels, D., and Bouma, J.: Soil structure assessment, Balkema, Rotterdam, The Netherlands, 1986.

Campbell, G. S. and Norman, J. M.: An introduction to environmental biophysics. Springer, New York, 286 pp., 1998
Chehbouni, A., Nichols, W. D., Njoku, E. G., Qi, J., Kerr, Y., and Cabot, F.: A three component model to estimate sensible heat flux over sparse shrubs in Nevada, Rem. Sens. Rev., 15, 99-112, 1997.

Choudhury, B. J., Ahmed, N. U., Idso, S. B., Reginato, R. J., and Daughtry, C. S. T.: Relations between evaporation coefficients and vegetation indices studied by model simulations, Rem. Sens. Environ., 50, 1-17, 1994.

Ciraolo, G., D’Urso, G., and Minacapilli, M.: Actual evapotranspiration estimation by means of airborne and satellite remote sensing data, in: Proc. Remote Sensing for Agriculture, Ecosystems and hydrology VIII, edited by: Owe, M., D’Urso, G., and Neale, C., SPIE Europe, Stockholm, Italy, 2006.

Clevers, J. G. P. W.: The application of a weighted infrared-red vegetation index for estimating leaf area index by correcting for soil moisture, Rem. Sens. Environ., 29, 25-37, 1989.

Crago, R. D.: Conservation and variability of the evaporative fraction during the daytime, J. Hydrol., 180, 173-194, 1996.

Crippen, R. E.: Calculating the Vegetation Index Faster, Rem. Sens. Environ., 34, 71-73, 1990.

Crown, W. T., Kustas, W. P., and Prueger, J. H.: Monitoring rootzone soil moisture through the assimilation of a thermal remote sensing-based soil moisture proxy into a water balance model, Rem. Sens. Environ., 112, 1268-1281, 2008.

D'Urso, G., Menenti, M., and Santini, A.: Regional application of one-dimensional water flow models for irrigation management. Agricultural Water Management, Elsevier, 40, 291-302, 1999.

D’Urso, G. and Minacapilli, M.: A semi-empirical approach for surface soil water contentestimation from radar data without apriori information on surface roughness, J. Hydrol., $321297-$ 310, 2006.

D'Urso, G.: Simulation and management of on-demand irrigation systems: a combined agrohydrological and remote sensing approach. Monography, Wageningen University, ISBN 90-5808399-3,174 pp., 2001.

Dane, J. H. and Hopmans, J. W.: Water retention and storage: laboratory, in: Methods of Soil Analysis. Part 4. Physical Methods, edited by: Dane, J. H. and Topp, G. C., Soil Sci. Soc. Am. Book Series No.5. Madison, WI, 688-692, 2002.

Doorenbos, J. and Kassam, A. H.: Yield response to water. FAO Irrigation and Drainage Paper 33, Food and Agricultural Organization of the United Nations, Rome, 1979.

Droogers, P., Bastiaanssen, W. G. M., Beyazgul, M., Kayam, Y., Kite, G. W., and Murray-Rust, H.: Distributed agro-hydrological modeling of an irrigation system in western Turkey, Agric. Water Manage., 43, 183-202, 2000.

Feddes, R. A., Kowalik, P. J., and Zaradny, H.: Simulation of field water use and crop yield, Monographs, Pudoc (Centre for Agricultural Publishing and Documentation), Wageningen, 189 pp., 1978.

Gao, Y. and Long, D.: Intercomparison of remote sensing-based models for estimation of evapotranspiration and accuracy assessment based on SWAT, Hydrol. Processes, 22, 4850-4869, 2008.

Goudriaan, J.: Crop micrometeorology: a simulation study, Center for Agric. Publ. and Doc., Wageningen, The Netherlands, 1977.

Immerzeel, W. W., Gaur, A., and Zwart, S. J.: Integrating remote sensing and a process-based hydrological model to evaluate water use and productivity in a south Indian catchment, Agric. Water Manage., 95, 11-24, 2008 
Kalma, J. D. and Jupp, D. L. B.: Estimating evaporation from pasture using infrared thermometry: evaluation of a one-layer resistance model, Agric. For. Meteorol., 51, 223-246, 1990.

Kroes, J. G., Wesseling, J. G., and Van Dam, J. C.: Integrated modelling of the soil-water atmosphere-plant system using the model SWAP 2.0, an overview of theory and an application, Hydrol. Processes, 14, 1993-2002, 2000.

Kustas, W. P. and Norman, J. M.: Evaluation of soil and vegetation heat flux predictions using a simple two-source model with radiometric temperature for partial canopy cover, Agric. For. Meteorol., 94, 13-29, 1999.

Kustas, W. P., Anderson, M. C., Norman, J. M., and Li, F.: Utility of radiometric-aerodynammic temperature relations for heat flux estimation, Bound.-Lay. Meteorol., 122, 167-187, 2007.

Liang, S.: Qantitative Remote Sensing of Land Surface, J. Wiley \& Sons, Inc., Publication, 528 pp., 2004.

Liu, J.: A GIS-based tool for modelling largescale crop-water relations. Environ. Model. Software, 24(3), 411-422, 2009.

Menenti, M. and Choudhury, B. J.: Parameterization of land surface evaporation by means of location dependent potential evaporation and surface temperature range, in: Exchange Processes at the Land Surface for a Range of Space and Time Scales, edited by: Bolle, H. J., Feddes, R. A., and Kalma, J. D., 561-568, IAHS Publ., 212, IAHS Press, Wallingford, UK, 1993.

Minacapilli, M., Ciraolo, G., and D'Urso, G.: Evaluating actual evapotranspiration by means of multi-platform remote sensing data: a case study in Sicily, (Proceedings of Symposium HS3007 at IUGG2007, Perugia, July 2007), IAHS Publ., 316, 2007.

Minacapilli, M., D’Urso, G., and Qiang, L.: Applicazione e confronto dei modelli SAIL e CLAIR per la stima dell'indice di area fogliare da dati iperspettrali MIVIS (A comparison between SAIL and CLAIR models for LAI estimation from hyperspectral MIVIS data), Rivista Italiana di Telerilevamento, 33, 15-25, 2005 (in Italian with English abstract).

Minacapilli, M., Iovino, M., and D'Urso, G.: A distributed agrohydrological model for irrigation water demand assessment, Agric. Water Manage., 95, 123-132, 2008.

Norman, J. M., Kustas, W. P., and Humes, K. S.: A two-source approach for estimating soil and vegetation energy fluxes in observations of directional radiometric surface temperature, Agric. For. Meteorol., 77, 263-293, 1995.

Priestley, C. H. B. and Taylor, R. J.: On the assessment of surface heat flux and evaporation using large-scale parameters, Mon. Weather Rev., 100, 81-92, 1972.

Ragab, R.: A holistic generic integrated approach for irrigation, crop and field management: the SALTMED model, Env. Model. Software, 17, 345-361, 2002.

Reynolds, W. D., Elrick, D. E., Young, E. G., Booltink, H. W. G., and Bouma, J.: Saturated and field-saturated water flow parameters: water transmission parameters: Laboratory methods, in: Methods of Soil Analysis. Part 4. Physical Methods, edited by: Dane, J. H. and Topp, G. C., Soil Sci. Soc. Am. Book Series No.5. Madison, WI, 802-817, 2002.

Richards, L. A.: Capillary conduction of liquids through porous mediums, Physics, 1, 318-333, 1931.
Savige, C., Western, A., Walker, J. P., Kalma, J. D., French, A., and Abuzar, M.: Obtaining surface energy fluxes from remotely sensed data, in: Proc. Modelling and Simulation, edited by: Zerger, A. and Argent, R. M., 2946-2952, MODSIM 2005 Society of Australia and New Zealand, 2005.

Sentek: Diviner 2000: user guide, version 1.21, Stepney: Sentek PTy LTd, 2000.

Schultz, G. A. and Engman, E. T. (Eds.): Remote Sensing in Hydrology and Water Management, Springer-Verlag Inc., New York, USA, 473 pp., 2000.

Schumugge, T. J., Kustas, W. P., Ritchie, J. C., Jackson, T. J., and Rango, A.: Remote sensing in hydrology, Adv. Water Resour., 25, 1367-1385, 2002.

Shuttleworth, W. J. and Gurney, R. J.: The theoretical relationship between foliage temperature and canopy resistance in sparse crop, Q. J. Roy. Meteorol. Soc., 116, 497-519, 1990.

Shuttleworth, W. J. and Wallace, J. S.: Evaporation from sparse crops - an energy combination theory, Q. J. Roy. Meteorol. Soc., 111, 839-855, 1985.

Slater, P., Biggar, S., Thome, K., Gellman, D., and Spyak, P.: Vicarious radiometric calibrations of EOS sensors, J. Atmos. Ocean Technol., 13, 349-359, 1996.

Su, Z.: The Surface Energy Balance System (SEBS) for estimation of turbulent heat fluxes, Hydrol. Earth Syst. Sci., 6, 85-100, 2002,

http://www.hydrol-earth-syst-sci.net/6/85/2002/.

Taylor, S. A. and Ashcroft, G. M.: Physical Edaphology. The Physics of irrigated and non-irrigated soils. Freeman, San Francisco, CA, 563 pp., 1972.

Van Dam, J. C., Huygen, J., Wesseling, J. G., Feddes, R. A., Kabat, P., Van Walsum, P. E. V., Groenendijk, P., and Van Diepen, C. A.: Theory of SWAP version 2.0. Simulation of water flow, solute transport and plant growth in the Soil-Water-Atmosphere-Plant environment, Technical Document 45, Wageningen Agricultural University and DLO Winand Staring Centre, The Netherlands, 1997.

Van Genuchten, M. T., Leij, F. J., and Yates, S. R.: The RETC code for quantifying the hydraulic functions of unsaturated soils. Report No. EPA/600/2-91/065, US Environmental Protection Agency, Office of Research and Development, Washington, D.C., 1991.

Van Genuchten, M. T.: A closed form equation for predicting the hydraulic conductivity of unsaturated soils, Soil Sci. Soc. Am. J., 44, 892-898, 1980.

Vanclooster, M., Viane, P., Diels, J., and Christiens, K.: Wave. A mathematical model for simulating water and agrochemicals in the soil and vadose environment. Reference and user's manual (release 2.0). Institute for Land and Water Management, Katholieke Universiteit Leuven, Leuven, Belgium, 1994.

Wesseling, J. G., Elbers, J. A., Kabat, P., and Van den Broek, B. J.: SWATRE: instructions for input. Internal note, Winand Staring Centre (alterra), Wageningen, The Netherlands. International Waterlogging and Salinity Research Institute, Lahore, Pakistan, 29 pp., 1991. 